\title{
Os distanciamentos entre a Base Nacional Comum Curricular e a etnomatemática
}

\author{
Adriano Vargas Freitas 1 ic \\ Universidade Federal Fluminense (UFF), Faculdade de Educação, Niterói, RJ, Brasil \\ Maria Cecilia Fantinato ${ }^{2}$ iD \\ Universidade Federal Fluminense (UFF), Faculdade de Educação, Niterói, RJ, Brasil
}

\begin{abstract}
Resumo
$\mathrm{O}$ artigo destaca um dos mais recentes documentos que influenciam diretamente as políticas educacionais em nosso país, a Base Nacional Comum Curricular da educação básica. Tal documento tem sido apresentado como definidor dos direitos de aprendizagens de todos os alunos, e parte de um projeto educacional que visa orientar implementações curriculares em todas as escolas, assim como direcionar a formação de professores. Analisamos, entretanto, que sua implementação envolve a redução de currículos a objeto, a produto, a lista de conteúdos previamente dados. Além disso, passa a significar um processo de colonização, padronização, controle, e invisibilização da diferença. Desta forma, ele se distancia de práticas curriculares alinhadas às perspectivas etnomatemáticas.
\end{abstract}

Palavras-chave: Base Nacional Comum Curricular; Etnomatemática; Currículos.

\section{The distances between the Common National Curriculum Base and ethnomathematics}

\begin{abstract}
The article highlights one of the most recent documents that directly influence educational policies in our country. This document is the Common National Curriculum Base for basic education. This document has been presented as defining the learning rights of all students. It is part of an educational project that aims to guide curriculum implementation in all schools. He will also direct teacher training. However, we analyze that its implementation involves the reduction of curricula to an object, a product, the list of previously given contents. Furthermore, it comes to mean a process of colonization, standardization, control, and making difference invisible. In this way, he distances himself from curricular practices aligned with ethnomathematic perspectives.
\end{abstract}

Keywords: Common National Curriculum Base; Ethnomathematics; Resumes.

Submetido em: 26/06/2021 Aceito em: 18/08/2021 Publicado em: 03/09/2021

\footnotetext{
${ }^{1}$ Doutor em Educação Matemática pela PUC-SP. Professor do Programa de Pós-Graduação em Educação da UFF. Email: adrianovargas@id.uff.br

2 Doutora em Educação pela USP. Professora do Programa de Pós-Graduação em Educação da UFF. E-mail: mc_fantinato@id.uff.br
} 


\section{Las distancias entre la Base Curricular Nacional Común y las etnomatemáticas}

\section{Resumen}

El artículo destaca uno de los documentos más recientes que inciden directamente en las políticas educativas de nuestro país. Este documento es la Base Curricular Nacional Común para la educación básica. Se ha presentado como una definición de los derechos de aprendizaje de todos los estudiantes. Es parte de un proyecto educativo que tiene como objetivo orientar la implementación del plan de estudios en todas las escuelas, así como la formación directa de profesores. Analizamos, sin embargo, que su implementación implica la reducción de los currículos a un objeto, un producto, la lista de contenidos previamente dados. Además, se trata de un proceso de colonización, estandarización, control y invisibilización de la diferencia. De esta forma, se distancia de las prácticas curriculares alineadas con las perspectivas etnomatemáticas.

Palabras clave: Base de currículo nacional común; Etnomatemáticas; campo del plan de estudios.

\section{Introdução}

Neste artigo destacamos um dos mais recentes documentos que influenciam diretamente as políticas educacionais, a Base Nacional Comum Curricular (BNCC) da educação básica. Ela tem sido apresentada pelos seus defensores como o documento definidor dos "direitos de aprendizagens de todos os alunos do Brasil" (Fundação Lemann, 2020) ${ }^{3}$, como parte de um projeto educacional homogeneizador, que visa orientar implementações curriculares em todas as escolas.

A BNCC determina os conhecimentos e as habilidades essenciais que todos os alunos e alunas têm o direito de aprender. Na prática, isso significa que, independentemente da região, raça ou classe socioeconômica, todos estudantes do Brasil devem aprender as mesmas habilidades e competências ao longo da sua vida escolar (LEMANN, 2020, p. 1).

Vale destacar que desde a implementação da Constituição Federal de 1988, que apresenta em seu artigo 206 as indicações de que o ensino no país será ministrado com base em alguns princípios essenciais, tais como o da igualdade, que significaria a promoção das necessárias condições para a o acesso e permanência na escola, e o da liberdade de aprender, ensinar, pesquisar e divulgar o pensamento, a arte e o saber. Entretanto, uma parcela da sociedade ansiava em dar maior destaque a um outro artigo, especificamente o de número 210, que indica a fixação de "conteúdos mínimos para o ensino fundamental, de maneira a assegurar formação básica comum e respeito aos valores culturais e artísticos, nacionais e regionais" (BRASIL, 1988, p. 109).

\footnotetext{
3 A Fundação Lemann mantém uma página na internet "O que é a BNCC?". Endereço: https:// funda cao lemann.org.br/noticias/o-que-e-a-bncc?gclid=EAIaIQobChMIotLc2vrC6wIVAgeRCh2J3QlUEAAYASAAEgKB D BwE. Acesso em 30/04/2021.
} 
Em busca de atingirmos essa pseudo unidade nacional, posteriormente reiterada na Lei de Diretrizes e Bases da Educação Nacional (BRASIL, 1996), surge então, a BNCC, cuja homologação da parte referente à educação infantil e do ensino fundamental ocorreu em 2017.

A Base Nacional Comum Curricular vai deixar claro os conhecimentos essenciais aos quais todos os estudantes brasileiros têm o direito de ter acesso e se apropriar durante sua trajetória na Educação Básica, ano a ano, desde o ingresso na Creche até o final do Ensino Médio. Com ela os sistemas educacionais, as escolas e os professores terão um importante instrumento de gestão pedagógica e as famílias poderão participar e acompanhar mais de perto a vida escolar de seus filhos. A Base será mais uma ferramenta que vai ajudar a orientar a construção do currículo das mais de 190 mil escolas de Educação Básica do país, espalhadas de Norte a Sul, públicas ou particulares. Com a Base, ficará claro para todo mundo quais são os elementos fundamentais que precisam ser ensinados nas Áreas de Conhecimento: na Matemática, nas Linguagens e nas Ciências da Natureza e Humanas. A Base é parte do Currículo e orienta a formulação do projeto Político-Pedagógico das escolas, permitindo maior articulação deste. (BRASIL, 2019, p.1)

O trecho acima apresentaria um chamado para a sociedade participar da implementação da BNCC, que estaria prometendo a organização dos elementos fundamentais "que precisam ser ensinados" em nossas escolas. Entretanto, pelo fato de ser um documento com poucos espaços para questões prementes como cultura e diferença, suscita uma série de questões ainda em aberto, tais como: A quem interessou a implementação desta BNCC? Que sentidos de currículo foram articulados nestas políticas curriculares? Estabelecer o mínimo garante de fato a qualidade de educação? O que é uma educação de qualidade? Base é simplesmente uma lista de conteúdos? Aliada a estas, muitas outras questões poderiam ser aqui elencadas ainda, tais como indicar o que é Comum Nacional?

\section{A implementação da BNCC}

Para Santos (2017, p. 4), a pressão pela implementação da BNCC teria partido dos sistemas de avaliação e dos gestores dos órgãos centrais dos sistemas de ensino como forma de aferir o processo educacional, oferecendo "parâmetros mais concretos para as avaliações". A autora destaca que os acadêmicos da área de currículos expressam a impossibilidade de que, na prática, a BNCC represente a qualidade da educação, assim como a garantia de qualidade do processo de ensino e de aprendizagem, ressaltando que este documento será reinterpretado/recontextualizado de acordo com as experiências e as tradições das diferentes esferas (secretarias educacionais, pela escola, pelo professor, e pelo estudante).

Ao lado disso, essa base nacional comum, na forma como está sendo proposta, vai de encontro às políticas de inclusão, porque contraria o direito à diferença. A BNCC 
parece diferir de outras políticas do próprio Ministério da Educação. [...] Qualquer especialista nessas áreas sabe que diferença e diversidade não podem ser alcançadas a partir de uma base nacional comum (SANTOS, 2017, p.4).

Este posicionamento encontra respaldo no documento da Associação Nacional de Pósgraduação e Pesquisa em Educação (ANPED, 2016), que denuncia o caráter mercadológico que envolve a proposta, cedendo voz a um projeto unificador "na direção que apontam as tendências internacionais de uniformização/centralização curricular + testagem larga escala + responsabilização de professores e gestores" (ANPED, 2016, p.2).

Mesmo antes da publicação deste documento produzido pela ANPED, Macedo (2014) já ressaltava a complexa relação público-privada envolvida na construção da BNCC, destacando que foram muitas as instituições financeiras e empresas que apresentaram grande interesse nessa construção. Dentre estas empresas podemos destacar: o banco Itaú, o banco Bradesco, o banco Santander, a indústria siderúrgica Gerdau, a empresa de cosméticos Natura, a montadora Volkswagen, a Fundação Victor Civita, a Fundação Roberto Marinho, e a Fundação Lemann.

Nesse processo de construção do documento, os sentidos empregados de "comum" e de "nacional" ignoraram, de uma forma geral, processos democráticos de participação plena de educadores e pesquisadores da área, e incitaram a busca por resultados, estes impregnados pela suposta neutralidade e pela frieza dos padrões e dos "bons índices", tão desejados pelo mercado.

Dessa forma, podemos considerar que este documento configura uma perspectiva de currículo que reduz a complexidade do campo. O currículo passaria a ser reduzido a objeto, a produto, a uma lista de conteúdos previamente dados. Além disso, passa a significar a padronização, a homogeneização, a regulação, o controle, e, é claro, a invisibilização da diferença.

Ribeiro e Freitas (2018) analisam que as mudanças no cenário político do país têm tentado minar debates relacionados a questões que envolvem estas complexidades do campo do currículo, e que este curso histórico parece estar permitido sobressair uma força conservadora crescente no exercício do poder. A título de exemplificação, destacam o movimento denominado de "Escola sem Partido" que defendeu publicamente a BNCC, e que buscou a implementação de uma série de medidas contra gestões democráticas nas escolas, visando inclusive

[...] influenciar a ação de pais e alunos através da cultura da delação contra "os ideólogos", sobretudo, os professores da escola básica, supondo que boa parte deles impõe uma ideologia partidária aos seus alunos, os quais têm sido tratados pelos defensores deste movimento como "audiência cativa" (RIBEIRO e FREITAS, 2018, p. 40). 
Muito do que acompanhamos nas campanhas defensoras deste documento, esteve calcado em argumentos relacionados à percepção da existência de uma crise na educação, de professores mal formados, na incompetência do estado na administração pública, etc. (MACEDO, 2014), e que todo esse quadro seria melhorado com a implementação de uma proposta salvacionista e inovadora que, supostamente, irá garantir os direitos de aprendizagem e desenvolvimento dos estudantes por meio da definição de conteúdos mínimos.

Garcia e Fontoura (2015) analisam que estes discursos têm esvaziado o sentido desta expressão, “direitos de aprendizagem”, uma vez que estes direitos passam a ser reduzidos a um simples conjunto de conteúdos e habilidades a serem alcançadas. Considerando não apenas que este conjunto já aparece pronto para que os professores desenvolvam em suas atividades juntos aos estudantes, mas também por sabermos que é comum que o "mínimo" se torne o "máximo" em uma política de resultados. Em outras palavras, o que vale é o que "cai na provinha".

\section{Distanciamentos de perspectivas etnomatemáticas}

A máxima de que currículo é um campo de disputas talvez tenha em toda essa situação, de construção e implementação da BNCC, um dos exemplos mais simbólicos. Não obstante, o que enfatizam Ribeiro e Freitas (2018), a abordagem curricular de cunho mais conservador não difere muito nem de um discurso neoliberal, em alguns aspectos importantes, uma vez que currículo é pensado por eles como um objeto, um documento, como "uma arma" para mudar a educação, sobretudo porque compartilham da ideia de que há um conjunto de conhecimentos universais.

Tais concepções vão na contramão do que pesquisas da área da educação matemática têm apontado (FREITAS, 2013), no intuito de superar antigos problemas da área relacionados ao distanciamento das atividades curriculares desenvolvidas nas salas de aula, e o cotidiano e as experiências/vivências dos estudantes. A indicação de práticas curriculares embasadas em perspectivas etnomatemáticas seria um possível caminho para incorporar saberes anteriores dos estudantes, e abrir espaços dialógicos para a valorização e incorporação nas práticas curriculares de questões relacionadas diretamente às especificidades sociais, culturais e políticas dos aprendentes. Assim propiciariam a formação de cidadãos críticos, e possibilitaria tornar visível os diferentes saberes culturais (FANTINATO, 2004; KNIJNIK, 2006; FANTINATO, FREITAS e DIAS, 2020).

Para D’Ambrosio (2001), é lamentável a existência de propostas de organização escolar que estejam fundamentadas em processos de homogeneização educacional que ainda insistem em "colocar crianças em séries de acordo com a idade, em oferecer o mesmo currículo numa mesma série" (p.61), e ainda mais lamentável, segundo este autor, propostas de currículos nacionais, pois 
"trata-se efetivamente de pasteurizar as novas gerações" (p.61), e diminuir espaços para o saber cotidiano e para a diversidade.

Uma boa educação não será avaliada pelo conteúdo ensinado pelo professor e aprendido pelo aluno. $\mathrm{O}$ desgaste do paradigma educacional sintetizado no binômio “ensino-aprendizagem". Verificado por avaliações inidôneas, é insustentável. [...] minha proposta é uma resposta educacional às expectativas de se eliminar iniquidade e violações da dignidade humana, o primeiro passo para a justiça social. (D’AMBROSIO, 2001, p.66).

Uma proposta curricular que leve em conta a diversidade não deveria considerar apenas os aspectos relacionados aos conteúdos, ou às habilidades no processo de ensino e de aprendizagem, pois o reconhecimento da identidade cultural dos educandos é fundamental ao seu desenvolvimento educacional. Assim, a etnomatemática tomada como proposta de referência, poderia estimular nos docentes atitudes de emersão de modos de raciocinar dos educandos, legitimando saberes construídos em diferentes contextos e favorecendo a construção de estratégias pedagógicas que lidem com as aprendizagens de fora da escola e da escola (DOMITE, 2004).

A complexidade do diálogo entre diferentes tipos de saberes no contexto escolar, tem permeado as discussões curriculares na perspectiva etnomatemática (MONTEIRO e MENDES, 2014). Ressaltamos ainda que, em perspectivas etnomatemáticas, propostas curriculares matemáticas deveriam sempre envolver a busca por uma formação humana integrada às diferentes dimensões da vida, estando esse projeto educacional comprometido efetivamente com a superação das desigualdades e injustiças sociais.

O desafio imposto consistiria na busca pela conciliação da necessidade de ensinar a "matemática dominante ao mesmo tempo dar reconhecimento para a etnomatemática e as tradições" (D’AMBROSIO, 2001, p.24) nas quais estão imersos esses indivíduos. Entretanto, da forma como se apresenta, a BNCC, impositiva em relação às habilidades a serem desenvolvidas em cada série, deixaria poucos espaços para que o docente promova o aproveitamento das vivências dos estudantes como forma de envolvê-los nas atividades matemáticas e mantê-los participantes de todo o processo educativo.

Este documento pode acabar impondo às práticas curriculares uma "roupagem tradicional, basicamente no formato expositivo" (FREITAS, 2013, p.72), com pouco ou nenhum espaço para diálogo, reflexão, criação coletiva, ou ainda a possibilidade de rememorar e expor suas experiências em matemática. Afinal, um grande número de suas habilidades estão envoltas a ações marcadamente técnicas, tais como: “(EF03MA09) associar o quociente de uma divisão com resto zero de um número natural por 2, 3, 4, 5 e 10 às ideias de metade, terça, quarta, quinta e décima partes” (BRASIL, 2017, 
p. 285); “(EF02MA09) Construir sequências de números naturais em ordem crescente ou decrescente a partir de um número qualquer, utilizando uma regularidade estabelecida" (BRASIL, 2017, p. 281); “(EF03MA15) classificar e comparar figuras planas (triângulo, quadrado, retângulo, trapézio e paralelogramo) em relação a seus lados (quantidade, posições relativas e comprimento) e vértices" (BRASIL, 2017, p. 287); ou ainda, (EF03MA26) resolver problemas cujos dados estão apresentados em tabelas de dupla entrada, gráficos de barras ou de colunas" (BRASIL, 2017, p. 287).

Convém destacar que um outro número de habilidades descritas no mesmo documento, podem ser desenvolvidas em perspectivas mais complexas, no sentido de distanciarem-se de serem apenas técnicas. A título de exemplificação, destacamos: “(EF01MA19) Reconhecer e relacionar valores de moedas e cédulas do sistema monetário" (BRASIL, 2017, p. 279), por exemplo, poderia ser relacionado à reflexões sobre salários e gastos mensais; ou ainda, “(EF03MA05) Utilizar diferentes procedimentos de cálculo mental e escrito para resolver problemas significativos envolvendo adição e subtração com números naturais" (BRASIL, 2017, p. 285), poderia ser desenvolvido por meio da valorização, oral ou escrita, de formas diferentes das tradicionalmente apresentadas pelos docentes, de formas resolutivas de problemas do cotidiano dos estudantes da EJA.

Importante salientar a influência que esta política pública exerce sobre as demais, tais como, e de forma especial, o Programa Nacional do Livro Didático (PNLD), que distribui de forma gratuita livros e outros materiais didáticos para os estudantes da rede pública de ensino.

O alinhamento dos materiais didáticos à BNCC é essencial para dar suporte tanto à aprendizagem dos alunos quanto à formação dos professores considerando os conhecimentos, habilidades e competências que o documento determina. Esse alinhamento é feito por meio do Programa Nacional do Livro Didático, o PNLD (MOVIMENTO PELA BASE, 2020, p.1).

De acordo com dados do Fundo Nacional de Desenvolvimento da Educação ${ }^{4}$, entre 2019 e 2020, cerca de 32 milhões de estudantes em 123 mil escolas foram beneficiadas pelo PNLD. Todo esse material deve seguir as normas, as orientações e as habilidades estabelecidas pela BNCC, conseguindo, desta forma, fazer com que a implementação deste documento se cumpra de forma abrangente, facilitando assim a implementação posterior dos próximos passos que envolveriam a formação de professores para a utilização destes materiais e da própria BNCC, e a aplicação de avaliações e monitoramentos dos processos de ensino e de aprendizagem (UNDIME, 2019, p.4).

4 Página disponível no endereço: https://www.fnde.gov.br/index.php/programas/programas-do-livro/pnld/dadosestatisticos. Acesso em 07/09/2020. 


\section{Considerações finais}

A percepção do quanto todo esse processo se distancia de propostas alinhadas à etnomatemática transparece em reflexões propostas por D’Ambrosio (2021) que, ao ser questionado a respeito da $\mathrm{BNCC}$ ser considerada como um processo de colonização e padronização, ressalta que propostas deste tipo são imposições que visam controlar, e que vão na contramão da proposta etnomatemática que envolveria "deixar a criança pensar, criar, dar oportunidade, provocar, fazer coisas" (p.12).

Desse jeito você não tem educação, o que você tem é doutrinação, disciplinação. E com isso, cria o indivíduo sem nenhuma capacidade crítica, sem nenhuma capacidade de reflexão sobre o que está se passando, sobre o que ele representa no contexto. Não tem capacidade. Como eu vou resolver este problema? Vou esperar as instruções que vêm. Sou mandado fazer isso e eu faço. [...] Tudo isso eu acho que tem que ser analisado nesse contexto (D’AMBROSIO, 2021, p.12).

Essa disciplinação distanciaria as práticas curriculares matemáticas de possibilidades de “conhecer-com em vez de conhecer-sobre" (SANTOS, 2019, p. 216), retirando autonomia dos docentes na busca de respeitar ritmos e interesses diferenciados de aprendizagem de seus alunos, diminuindo os espaços nos quais poderiam estar presentes os conhecimentos provenientes, por exemplo, das lutas de resistência contra o conhecimento único, dominante e colonizador.

O "conhecer-com" não envolve receitas mecânicas, pela sua intrínseca valorização da diversidade, em um movimento de luta contra a dominação, de diferentes modos. Esse movimento, de acordo com Santos (2019, p.216) envolve partilhar ações e experiências, abrir o passado para melhor compreender o presente e o futuro, e abrir diálogos com os homens e com a natureza.

\section{Referências}

ANPED. Associação Nacional de Pós-Graduação e Pesquisa. Exposição de motivos sobre a Base Nacional Comum Curricular. Disponível em: <https://goo.gl/NHpWQj >. Acesso em: 24 set. 2016.

BRASIL. Constituição da República Federativa do Brasil. Casa Civil. Brasília-DF, 1988.

BRASIL. Lei de Diretrizes e Bases da Educação: Lei 9.394. Diário Oficial da União. Brasília-DF, 1996.

BRASIL. Base Nacional Comum Curricular. Ministério da Educação, Brasília, DF, 2017.

BRASIL. Nota oficial do Ministério da Educação (MEC). 2019. Disponível em http://basenacionalcomum.mec.gov.br/nota-oficial. Acesso em 20/07/2020. 
D’ AMBROSIO, Ubiratan. Etnomatemática: Elo entre as tradições e a modernidade. Belo Horizonte: Autêntica, 2001.

D’AMBROSIO, Ubiratam. Entrevista concedida ao Grupo de Etnomatemática da Universidade Federal Fluminense. Remat, 2021.

DOMITE, M. C. S. Da compreensão sobre formação de professores e professoras numa perspectiva etnomatemática. In: KNIJNIK, G.; WANDERER, F.; OLIVEIRA, C. J. (Orgs.) Etnomatemática: currículo e formação de professores. Santa Cruz do Sul: EDUNISC, 2004. p. 419-431.

FANTINATO, M. C. C. B. A construção de saberes matemáticos entre jovens e adultos do Morro de São Carlos. Revista Brasileira de Educação (ANPED), N. 27, 2004, p.109-124.

FANTINATO, Maria Cecilia; FREITAS, Vargas Freitas; DIAS, Julio Cesar de Moura. "Não olha para a cara da gente": ensino remoto na EJA e processos de invisibilização em contexto de pandemia. Zetetiké, Campinas, SP, v.28, 2020, p.1-16.

FREITAS, Adriano Vargas. Educação Matemática e Educação de Jovens e Adultos: estado da arte de publicações em periódicos (2000 a 2010). Tese de Doutorado em Educação Matemática. Pontifícia Universidade Católica de São Paulo, 2013.

GARCIA, Alexandra; FONTOURA, Helena A. da. "Guarda isso porque não cai na provinha": pensando processos de centralização curricular, sentidos de comum e formação docente. Revista eCurriculum. São Paulo, v. 13, n. 04, p. 751-774, out./dez. 2015.

KNIJNIK, G. “A vida deles é uma matemática”: regimes de verdade sobre a educação matemática de adultos do campo. Educação Unisinos. v10 (1), 2006.

LEMANN - Fundação. O que é a BNCC? Entenda os detalhes desta política educacional e o que ela muda na educação. Disponível em: https://fundacaolemann.org.br/noticias/o-que-e-abncc?gclid=EAIaIQobChMIotLc2vrC6wIVAgeRCh2J3QIUEAAYASAAEgK-B_D_BwE. Acesso em 01/09/2020.

MACEDO, Elizabeth. Base Nacional Curricular Comum: novas formas de sociabilidade produzindo sentidos para educação. Revista E-Curriculum, São Paulo, v. 2, n. 3, p. 1530-1555, out./dez. 2014.

MONTEIRO, A.; MENDES, J.R. A etnomatemática no encontro entre práticas e saberes: convergências, tensões e negociação de sentidos. Revista Latinoamericana de Etnomatemática V.7, N. 3, p.55-70, 2014.

MOVIMENTO PELA BASE. Materiais didáticos e a BNCC. 2020. Disponível em http://movimentopelabase.org.br/acontece/materiais-didaticos-e-bncc/. Acesso em 07/09/2020.

RIBEIRO, William de Goes; e FREITAS, Adriano Vargas. Pensando em diferença e em educação nas disputas pela Base Nacional Comum Curricular. In: FREITAS, Adriano Vargas. Questões curriculares e Educação Matemática na EJA: desafios e propostas. Jundiaí: Paco Editorial, 2018.

SANTOS, Boaventura de Souza. O fim do império cognitivo: a afirmação das epistemologias do Sul. Belo Horizonte: Autêntica, 2019. 
SANTOS, Luciola Licinio. Administrando o currículo ou os efeitos da gestão no desenvolvimento curricular. Educação em Revista. Belo Horizonte, 2017.

UNDIME. Implementação: Base Nacional Comum Curricular. 2019. Disponível em:

http://www.undime-sp.org.br/wp-content/uploads/2018/01/seminario3101silvia araujo.pdf. Acesso em 07/09/2020. 